\title{
Wheat in Pakistan and other Asian Countries
}

\section{J. H. M. OPDAM and P. A. CORNELISSE*}

\section{INTRODUCTION}

It seems as if in recent years the development literature has shifted weight towards the agricultural sector, thereby doing more justice to the relative importance of that sector in developing economies. The occurrence of the Green Revolution and, subsequently, the concern for its distribution effects have contributed to this shift. Another cause may have been the accusation of an urban bias in development economics and, particularly, in development policies. Or, more down to earth, the explanation may be simply that in the course of time it was realized that the neglect of wage goods - among which food products are prominent - creates a very serious bottleneck which eventually leads to inflation and balance-of-payments problems, not to mention social discontent and political tension.

Within agriculture, wheat is easily the most important single product - both as a food item and as a source of income - in many countries. The situation in Pakistan illustrates this point as wheat production in 1975-76 contributed 19.5 percent to private household income generated in agriculture, whereas the next largest product, rice, contributed 6.8 percent. $^{1}$ The shares of both products in private consumption in Pakistan show a similar pattern. Also, on a global scale, wheat is among the most important products both by the volume of production and by the extent to which it fulfils the basic need for food. This observation also explains the role wheat plays in geopolitics.

The importance of wheat in the economy of Pakistan has inspired the Pakistan Institute of Development Economics and the Centre for Development Planning at the Erasmus University, Rotterdam, to set up a detailed study of the wheat market in that country. The objectives, instruments and restrictions of the various groups

*At the time of the writing of this Note, Mr. Opdam was Research Fellow in the Centre for Development Planning, Erasmus University, Rotterdam (Netherlands), Dr. Cornelisse is Professor of Development Economics at the same university. The data used in this Note were drawn from a data base compiled by Mr. Opdam.

1

Figures derived from F. D. McCarthy and L. Taylor [7]. 
of actors in that market are to be examined in order to better understand their market position and behaviour. Groups of actors distinguished are: farmers; various levels and types (private and public) of wheat buyers (in monetary and non-monetary transactions); millers; policy-makers and public servants; and various types of flour sellers and consumers.

The purpose of this paper is to present and briefly discuss figures which describe a few selected aspects of the consumption, production and international trade of wheat in Asian countries. On some occasions, the performance of wheat will be compared with that of rice, the other main grain product. In international comparisons, special attention will be given to Pakistan.

\section{CONSUMPTION}

If one should wish to divide the countries of Asia by their wheat-consuming habits, a part of the demarcation line on the map would coincide with Pakistan's eastern border. It is a bold line, without the reservations and qualifications often necessary in economic analysis. West of it, the consumption of wheat per head per year is in nearly all cases at least a hundred kilograms, whereas to the east the corresponding figure is hardly much more than fifty kilograms. It appears that the same line can also serve to distinguish rice-eating countries from other countries, but now the order is reversed. On the eastern side, consumption of rice per head of the population is a hundred kilograms or more in nearly all cases and on the western side it is at most fifty kilograms. This symmetrical pattern is clearly illustrated in Table 1 where countries have been ordered according to their position on the map from west to east.

Rice is typically used for human consumption, and in the wheat-eating countries of Asia wheat largely performs the same role. This holds even for Turkey with its remarkably high level of wheat use. In other countries, however, low-quality wheat is sometimes also used as fodder, that is as an intermediate good for the production of milk and/or meat. Clearly, these two uses follow different patterns of behaviour. In particular, the sensitivity to opportunities for substitution may show a large difference. Further, it appears that in an international comparison of only one use of wheat, individual countries may demonstrate significantly different patterns. For these reasons, aggregate figures of the use of wheat per head of the population by countries sometimes seem to be hard to explain at first sight. For example, total wheat consumption per head per year during the period 1976-1980 was $117 \mathrm{kgs}$ in North America, $169 \mathrm{kgs}$ in the EC, $409 \mathrm{kgs}$ in the Soviet Union and $139 \mathrm{kgs}$ in Pakistan. Clearly, such differences cannot be explained simply by variations in purchasing power. This observation is also illustrated by the figures given in Table 1, although only partly so, because the complication caused by the use of wheat as fodder plays only an insignificant role there.
Table 1

Wheat and rice consumption (in kilograms) per head per year in selected Asian countries, 1980

\begin{tabular}{lcccc}
\hline Countries & Wheat & Rice & Wheat+Rice & Total Grains \\
\hline Turkey & 381 & - & - & 555 \\
Lebanon & 115 & - & - & 160 \\
Israel & 171 & 11 & 182 & 427 \\
Iraq & 191 & 46 & 237 & - \\
Iran & 179 & 43 & 222 & 308 \\
Saudi Arabia & 80 & 43 & 123 & 367 \\
Afghanistan & 190 & 28 & 218 & 290 \\
Pakistan & 125 & 44 & 169 & 199 \\
India & 52 & 124 & 179 & 216 \\
Sri Lanka & 53 & 70 & 123 & - \\
Nepal & - & 173 & - & 266 \\
China & 70 & 150 & 220 & 318 \\
Bangladesh & 26 & 241 & 267 & 277 \\
Burma & - & 316 & - & 383 \\
Thailand & - & 325 & - & 355 \\
Malaysia & - & 169 & - & - \\
Indonesia & 9 & 225 & 234 & 265 \\
Philippines & - & 154 & - & 235 \\
Korea DPR & - & 250 & - & 485 \\
Korea Rep. & 46 & 168 & 152 & 307 \\
Japan & 52 & 100 & & 315 \\
\hline
\end{tabular}

Sources: $[3] ;[6]$ and $[10]$.

Hence we conclude that in an international comparison of wheat use, aggregate figures carry only limited information. In general, an explanation of a country's use of wheat should be carried out in the context of a model treating simultaneously the use of both wheat and its substitutes and distinguishing between human and animal consumption and other uses of wheat. The results of such estimation exercises do not seem to be readily available, however. This may partly be due to technical complications involved by the statistical testing of the substitution possibilities. These can, of course, be avoided by limiting the analysis to the total volume of the various grains in use, but this approach would preclude any insight regarding the behaviour of the individual products. 
The extent to which countries tend to use relatively more of one grain than of another for human consumption depends, of course, not only on taste in the strict sense of the word. In most countries, domestic production appears to be a strong habit-creating factor in this respect. Often, dietary habits have been formed and strengthened by and over many generations and they tend to change only slowly even after the introduction of non-traditional grains in domestic production. Availability of imported grains, urbanization and exposure to other consumption habits abroad can bring about such changes, although, on the other hand, measures protecting traditional domestic grain production may limit the overall effect. A country like Japan, where the share of rice in total grain use dropped from 62 percent in the early 1960s to less than 40 percent in the late 1970s, is still an exception. These figures merely provide another illustration of the extraordinary social and economic developments which that country experienced in the recent decades.

During the same period the relative magnitude of wheat in total grain consumption in Pakistan dropped only slightly, although in absolute terms wheat consumption continued to increase. In the early 1960 s the share of wheat reached to 67 percent which at that time was the highest figure in the world. ${ }^{2}$ In the late 1970 s this share was about 62 percent and other countries had overtaken Pakistan in this respect. However, it cannot therefore be concluded that a continuous reduction of the concentration on wheat in Pakistan is to be expected, and even less that the saturation point of the consumption of wheat is at hand. During the period mentioned the share of imports in domestic supply of wheat has been reduced from 22 percent to about 13 percent, and it is possible that with a further growth of supply from domestic origin, the use of wheat will remain strong. A continuing urbanization can add to such an effect; the possible use of wheat as fodder is a subject of speculation. In other words, more time will have to pass before firmer conclusions as to developments in wheat consumption in Pakistan are feasible.

\section{PRODUCTION}

Table 2 gives an impression of the rise in the yield of wheat over the last two decades for a selected number of Asian countries. In almost all countries in table 2 yield has approximately doubled over the last twenty years. Notable exceptions are Japan on the one hand and Afghanistan, Iran, Lebanon on the other. In Japan yield was already on a high level at the beginning of the period under consideration. In the other countries, yield has been relatively stagnant at low levels. The rise in yield can be attributed to the introduction of high-yielding varieties of wheat during the period considered, combined with increased inputs of fertilizer, pesticides and introduction of water management. Neglect of these complimentary

${ }^{2}$ Rice can be a much more dominating grain. In five Asian countries, its share is still around 90 percent. inputs has prevented a full exploitation of the potential benefits of the green revolution in many cases. Although Pakistan has a well-known irrigation system, water supply together with low use of fertilizer are still considered to be bottleneck inputs for the growing of wheat [5]. Salination should be mentioned as another impediment to wheat growing in Pakistan, especially in the province of Sind.

Table 2

Yield of wheat (in kilograms per hectare) for selected Asian countries: 1960-61

\begin{tabular}{lcrrrr}
\hline Countries & 1960 & 1965 & 1970 & 1975 & 1980 \\
\hline Turkey & 1100 & 1075 & 1162 & 1593 & 1857 \\
Syria & 360 & 860 & 466 & 916 & 1540 \\
Jordan & 440 & 996 & 630 & 440 & 850 \\
Lebanon & 740 & 720 & 904 & 1053 & 1140 \\
Iraq & 460 & 590 & 703 & 603 & 867 \\
Iran & 780 & 912 & 836 & 979 & 1091 \\
Afghanistan & 980 & 972 & 956 & 1191 & 1125 \\
Pakistan & 798 & 863 & 1171 & 1320 & 1560 \\
India & 778 & 913 & 1208 & 1338 & 1440 \\
China & - & 960 & 1099 & 1367 & 1934 \\
Korea, Rep. of & 1272 & 1974 & 2259 & 2205 & 3300 \\
Japan & 2543 & 2706 & 2074 & 2678 & 3160 \\
& & & & & \\
\hline
\end{tabular}

Source: [4] and [6].

The figures on wheat yield in Table 2 do not show clearly the variance around the trend. This variance, however, appears to be an important contributing factor to the variance of production growth of wheat. The relation between these variances can be derived from a few simple formulas. Let

$$
X_{t}=A_{t} Y_{t}
$$

where $X_{t}=$ production of wheat during year $\mathrm{t}$;

$$
\begin{aligned}
& A_{t}=\text { area harvested; } \\
& Y_{t}=\text { yield }
\end{aligned}
$$

Define

$$
x_{t}=\ln \left(X_{t+1} / X_{t}\right)
$$

$$
a_{t}=\ln \left(A_{t+1} / A_{t}\right)
$$




$$
y_{t}=\ln \left(Y_{t+1} / Y_{t}\right)
$$

then the variance of the growth rate $x$ can be decomposed as

$$
V\left(x_{t}\right)=V\left(a_{t}+y_{t}\right)=V\left(a_{t}\right)+V\left(y_{t}\right)+2 V\left(a_{t}, y_{t}\right)
$$

where $V(a, y)$ is the covariance of $a$ and $y$.

The antilog of $V\left(x_{t}\right)$ multiplied by 100 is called the instability index [1, p.3] Such instability indices and their components according to the above formulas have been listed in Table 3 for selected Asian countries. With few exceptions the yield component contributes more to the total variance in production growth than the area component. The instability of production growth is relatively high in the countries of the middle east (Iraq, Lebanon, Syria, Jordan and Israel). Compared with those for other countries, the instability index for Pakistan is moderate. Indeed, the index for Pakistan equals approximately that for the USA or for Europe as a whole. This is the more remarkable, because the variance in yield tends to be less if the

Table 3

Decomposition of Instability Index for Wheat for

\begin{tabular}{|c|c|c|c|c|}
\hline \multirow{2}{*}{ Countries } & \multicolumn{3}{|c|}{ Variance } & \multirow{2}{*}{$\frac{2 \times \text { Covariance }}{(a, y)}$} \\
\hline & $\mathrm{x}$ & a & $y$ & \\
\hline Turkey & 5.70 & 0.30 & 4.35 & 1.04 \\
\hline Syria & 28.81 & 2.29 & 26.91 & -0.60 \\
\hline Lebanon & 8.43 & 4.45 & 3.13 & 0.85 \\
\hline Israel & 15.89 & 2.03 & 15.55 & -1.70 \\
\hline Jordan & 75.90 & 25.85 & 50.29 & -0.24 \\
\hline Iraq & 23.79 & 10.79 & 16.51 & -3.50 \\
\hline Iran & 1.70 & 0.46 & 1.67 & -0.44 \\
\hline Afghanistan & 1.16 & 0.86 & 1.96 & -1.66 \\
\hline Pakistan & 2.10 & 0.24 & 1.15 & 0.70 \\
\hline India & 1.67 & 0.51 & 1.15 & -0.06 \\
\hline China & 0.68 & 0.08 & 0.78 & -0.18 \\
\hline Burma & 13.47 & 6.07 & 4.02 & 3.38 \\
\hline Korea Rep. & 8.24 & 3.91 & 3.48 & 0.85 \\
\hline Japan & 6.96 & 2.01 & 4.63 & 0.32 \\
\hline
\end{tabular}
selected Asian countries

Source: country is larger, as crop conditions are more likely to vary over regions within large countries, such that variations in growth of production between regions tend to cancel out. This partly explains why the instability index for China is small. ${ }^{3}$ On the other hand, the variance of the growth of yield in Pakistan is probably underestimated by the official statistics. S. K. Qureshi [8] refers to a study of C. Beringer, showing that official production estimates have underestimated total wheat output on the average by about 21 percent and that there has been a tendency for official estimates to overestimate the actual output in poor seasons and to underestimate it in good seasons. Similar errors of measurement may be present in the figures of Table 3 for other countries as well.

In this context it is of interest that the instability indices for rice show significantly lower values. Compared to wheat yields those of rice tend to be subject to less variation. Computed instability indices for the yield of rice in selected Asian countries are below one in most cases. Apparently, the outcome of wheat growing is more uncertain. According to Steven Cheung this is the reason why, generally speaking, share tenancy is found more frequently in wheat regions than in rice regions [2, pp.70-71], because it provides the tenant better protection against the uncertainty of harvests. In the case of rice the desire to share the risk of variations in harvests is less urgent, so the landowner is more often able to charge the tenants a fixed amount.

\section{TRADE}

World wheat trade has varied between 16 to 20 percent of world wheat production during the last six years. Wheat trade is of special importance for Asian countries, which together hold a share in world imports of some 40 percent. But only four countries, viz. China, Japan, Bangladesh and the Republic of Korea account for approximately 50 percent of the Asian wheat imports. The importance of China as a wheat importing country has increased over the last ten years with import volumes of about 5 million tons per annum in the beginning of the seventies to over 8 million tons during the last few years. Until 1970 India imported annually from 20 percent to 40 percent of its total wheat consumption. Only recently the country has become self-supporting in wheat and has developed from a net importing to a net exporting country.

Not amazingly, wheat consumption in most rice-eating countries of Asia depends heavily on imports. Thailand, North and South Korea, Indonesia, Sri Lanka, the Philippines and Japan import between 60 percent and 100 percent of their wheat consumption. This observation is in accordance with the remark in

${ }^{3}$ In this context it is noteworthy that the computed instability index for the USSR over the period $1965-1977$ amounts to 6.3 . This instability is almost entirely attributable to the instability of yield per hectare (6.1). 
Section 2 on the consumption habit-creating effect of domestic production. Asian wheat imports are mainly obtained from Australia, Canada and the United States. For reasons of geographical distance Asia is the principal market outlet for Australian wheat. In recent years approximately 80 percent of the Australian wheat has been exported to Asia.

International effective demand for wheat varies only to a minor extent with international price. The price elasticity may be small for several reasons. First, it is well known, that by its very nature demand for raw materials in general shows only low to moderate reactions to price variations. Further, the Soviet Union, which as a centrally planned economy is less sensitive to price movements than market economies, has exerted a strong influence on market events during the last decade. Though its imports have been only a few percent of its domestic consumption, its share in total world imports has been considerable: during the last decade between 7 percent and 22 percent. Also on the Asian continent the price elasticity of wheat imports may differ by country. In rice-eating countries of Asia wheat can be considered as a secondary food item and perhaps as a luxury good. Imports in these countries can, therefore, be expected to be more sensitive to international price movements than in countries where wheat is a basic food as is the case in Pakistan. In this country subsidies on wheat consumption may further reduce price elasticity. To the extent that imports are price inelastic one may expect them to act as shock absorbers of variations in production and, thus, to vary inversely with production volumes. But changes in stocks can also assist in protecting consumption against erratic variations in wheat harvests. Therefore, in a simple relation as

$$
M_{t}-\bar{M}_{t}=a\left(X_{t-1}-\bar{X}_{t-1}\right)
$$

where $M_{t}=$ imports during crop year $\mathrm{t}$;

$$
\begin{aligned}
& \bar{M}_{t}=\text { trend value of imports in crop year } \mathrm{t} ; \\
& X_{t}=\text { production at the end of crop year } \mathrm{t} \text {; and } \\
& \bar{X}_{t}=\text { trend value of production in year } \mathrm{t} .
\end{aligned}
$$

one expects $a$ to assume a value between 0 and -1 . And indeed, if we specify exponential trends for both import demand and production in Pakistan during 1961 and 1979 , we find that $a=-0.42$ or, in other words, that the deviations from the trend values of imports absorb 42 percent of the deviations from production trend values. ${ }^{4}$ This coefficient is, however, statistically not very significant, because its

${ }^{4}$ The wheat harvesting period in Pakistan extends from March to the end of May. Conseently, deviations from production trend values have been correlated with deviations from

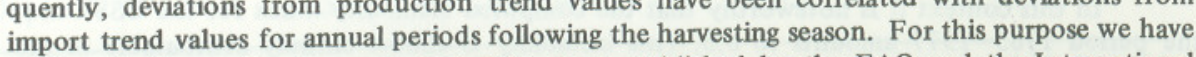
used trade figures for the crop year July-June, published by the FAO and the International Wheat Council. value depends heavily on the selection of the first and final year of the sample. Particularly, the import volumes do not show a clear trend. However, there is a clear suggestion of a negative correlation between the annual growth rates of production and imports. Deviations of year-to-year growth rates of production and import from their respective average annual growth rates have opposite signs in 15 out of 18 observations. Similar results with such a sign test are obtained if alternative specifications for the computation of trend values are used. In the case of Pakistan, therefore, it can be concluded tentatively, that imports of wheat dampen part of the effects of fluctuations in wheat harvest volumes. This pattern is not uncommon in international comparisons of wheat-import relations. ${ }^{5}$ Yet, some other countries appear to display different behavioural relations.

\section{REFERENCES}

1. Casley, D. J., and J. B. Simaika, R. P. Sinha. "Instability of Production and its Impact on Stock Requirements". Monthly Bulletin of Agricultural Econom ics and Statistics. Vol. 23, No. 5. 1974.

2. Cheung, Steven S. N. The Theory of Share Tenancy. Chicago/London: The University of Chicago Press. 1969.

3. FAO. Monthly Bulletin of Statistics. Vol. 4. Rome. 1981.

4. FAO. Production Yearbook. Rome. (Various volumes)

5. Gotsch, Carl and Gilbert Brown. Prices, Taxes and Subsidies in Pakistan Agriculture, 1960-1976. Washington, D.C.: World Bank. 1980. (World Bank Staff Working Paper No. 387)

6. International Wheat Council. World Wheat Statistics, 1981. London.

7. McCarthy, F. D., and L. Taylor. "Macro Food Policy Planning: a General Equilibrium Model for Pakistan". Review of Economics and Statistics. Vol. 62, No. 1. 1980. pp.107-121.

8. Qureshi, S. K. "Rainfall, Acreage and Wheat Production in West Pakistan: a Statistical Analysis". In S. M. Hussain and M. I. Khan, Empirical Studies on Pakistan Agriculture (Readings in Development Economics No. 3). Karachi: Pakistan Institute of Development Economics, 1969. pp.173-203.

9. Sarris, A. H., P. C. Abbott and L. Taylor. "Grain Reserves, Emergency Relief and Food Aid". In William R. Cline (ed.), Policy Alternatives for a New International Economic Order: an Economic Analysis. New York: Praeger Publishers. 1979.

10. World Bank. 1981 World Bank Atlas. Washington, D.C. 1982.

\footnotetext{
${ }^{5}$ See, for instance, A. H. Sarris et alii [9].
} 